\title{
Titanium Ti6Al4V alloy reinforced by the addition of nano yttria stabilized zirconia fabricated by selective additive manufacturing: microstructure and mechanical investigations
}

\author{
Amine HATTAL ${ }^{(a, b)}$, Madjid DJEMAI ${ }^{(b)}$, Jean Jacques FOUCHET ${ }^{(b)}$, Thierry CHAUVEAU ${ }^{(a)}$, Brigitte BACROIX ${ }^{(a)}$, Azziz HOCINI $^{(a)}$, Guy \\ $\operatorname{DIRRAS}^{(\mathrm{a})}$
}

(a) Université Paris 13, LSPM - CNRS, 99 avenue Jean Baptiste Clément, 932430, Villetaneuse, France

(b) Z3Dlab, Parc Technologique, 26 Rue des Sablons, Montmagny 95360, France

Keywords: Additive manufacturing; Ceramic; Selective laser melting; Zirconia; Ti6Al4V; Mechanical properties

\begin{abstract}
:
Additive manufactured Ti6Al4V reinforced with nano yttria-zirconia (nYSZ) parts were fabricated using selective laser melting technology (SLM). The as-received Ti6Al4V powder and two powder mixtures of Ti6Al4V mixed with several nYSZ contents (1wt\% and $2.5 \mathrm{wt} \%$ ) were prepared and then SLM processed. Parts were further subjected to a stress relief heat treatment. Besides, hot isostatic pressure (HIP) was used in order to eliminate residual porosities. The pycnometer-based technique was used to measure the mass density. XRD and EBSD analysis were performed to investigate the influence of nYSZ additions on the microstructure and subsequent mechanical properties via microhardness and compression tests. It was found that addition of nYSZ increases the density of the reinforced parts and produces a fine a martensite phase. Besides, the grain size was refined compared to that of heat treated Ti6Al4V. As a consequence, a significant increase in both the hardness and the compressive strength for the reinforced Ti6AI4V were obtained while the elongation to failure was kept. These improved mechanical properties are discussed in relation to the effect of nYSZ addition, which includes lattice distortions and strengthening from grain size refinement and/or a formation.
\end{abstract}

\section{Introduction}

Ti6Al4V is a titanium $a+\beta$ alloy with low density, high mechanical properties, excellent corrosion resistance and superior biocompatibility [1], which, because of its excellent properties is widely used in the aerospace industry (jet engines, gas turbines...) [2]. Over the past years, Ti6Al4V bulk and spare parts were and are still being manufactured via conventional methods such as casting, forging and rolling, which are all supplemented by machining in order to obtain the final desired shape. These processes result in significant material waste, high manufacturing cost and long lead time [3]. Additive manufacturing (AM) or 3D printing, as its name suggests, fabricates parts by adding successive layers of material under computer control [4] and 
considerably reduces material waste. Additionally, there are many attempts to enhance the mechanical properties of Ti6Al4V by combining AM with reinforced Ti6Al4V in order to create a reinforced titanium matrix [5-8]. However, most of the selected reinforcements are not well adapted to titanium as they usually induce a severe decrease of ductility [9]. nYSZ is a ceramic which presents a high hardness and fracture toughness compared to conventional ceramics [10], and also a high affinity with Ti6Al4V [11]. Mixtures of Ti6Al4V and Zirconia powders were prepared in recent years in order to manufacture parts by conventional manufacturing methods [12], but this powder mixture has not yet been used in AM. This paper reports and compares, for the first time, microstructure evolutions and mechanical properties characteristics of Ti6Al4V and Ti6Al4V-reinforced nYSZ fabricated by SLM and subsequent treatments allowing to reduce residual stresses and porosity.

\section{Material and experimental methods}

\subsection{Starting material and SLM process}

Powder batches of Ti6Al4V, Ti6Al4V mixed with $1 \mathrm{wt} \%$ and $2.5 \mathrm{wt} \% \mathrm{nYSZ}$ respectively were prepared and then melted using SLM to

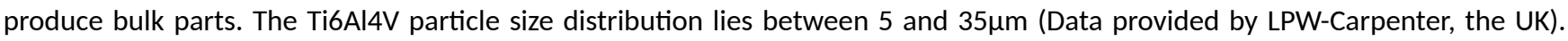
The nYSZ powder is a 3\%mol yttria-stabilized tetragonal zirconia with an average particle size of 40nm (Data provided by USnano, USA).

\subsection{SLM process}

The SLM melting process (Fig. 1) was developed and carried out at Z3DLAB (Paris-France) facility. The melting parameters were as follows: power: $200 \mathrm{~W}$; exposure: $100 \mu \mathrm{s}$; hatch spacing: $80 \mu \mathrm{m}$; point distance: $65 \mu \mathrm{m}$; layer thickness: $30 \mu \mathrm{m}$ and a chess scanning strategy in order to create parallelepiped parts having dimensions of about $10^{\prime} 10^{\prime} 10 \mathrm{~mm}^{3}$.

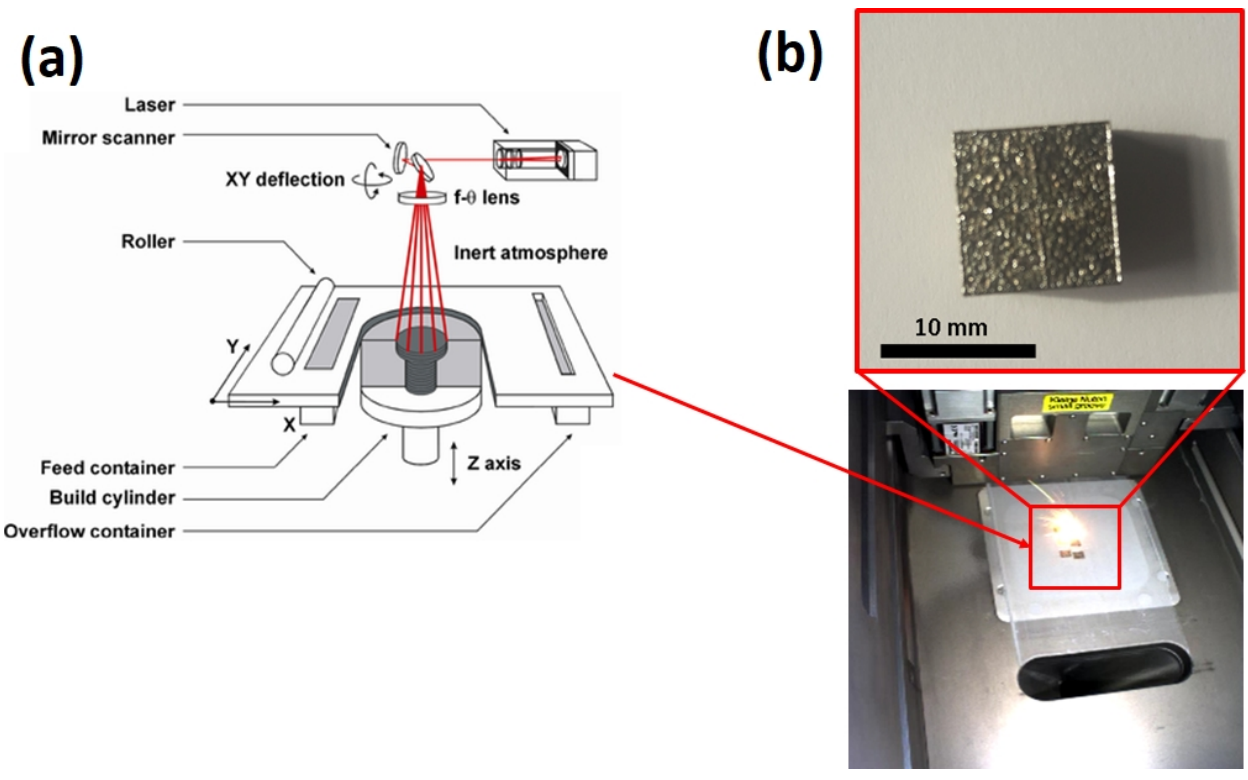

Figure 1: (a) SLM machine setup and the build parts [20], (b) the dimension of the melted part 
The mixture composition is listed in Table. 1. The additional stress relief heat treatment was performed according to AMS2801 standard, that is at $600^{\circ} \mathrm{C}$ during 2 hours. HIP post processing was conducted on the CARAMEL platform of the LSPM laboratory. HIP conditions were established to (920 C\%/2h/1000 bar).

Table. 1: Powder mixture composition (HT: stress relief heat treated) (HIP: Hot isostatic pressure)

\begin{tabular}{|c|c|c|c||}
\hline Ti6Al4V (wt\%) & $\begin{array}{c}\text { nYSZ } \\
\text { (wt\%) }\end{array}$ & After melting + HT & After melting + HT + HIP \\
\hline 100 & 0 & Ti6Al4V HT & Ti6Al4V HT HIP \\
\hline 99 & 1 & Ti6Al4V-1nYSZ HT & Ti6Al4V-1nYSZ HT HIP \\
\hline 97.5 & 2.5 & Ti6Al4V-2.5nYSZ HT & Ti6Al4V-2.5nYSZ HT HIP \\
\hline
\end{tabular}

\subsection{Density measurements}

Density measurements were performed for all parts using He pycnometer-based method.

\subsection{Microstructure observation}

Samples were polished mechanically with 600 to 4000 grids of SiC papers, followed by mirror polishing using nano silica solution (OPS). A scanning electron microscope (MEB FEG SUPRA 40VP-ZEISS) was used to perform electron backscatter diffraction (EBSD) on electropolished specimens using a step and a scan size of $0.6 \mu \mathrm{m}$ and $\left(550 \times 550 \mu \mathrm{m}^{2}\right)$ respectively. OIM software was used to perform EBSD data analysis.

\subsection{Mechanical properties}

Microhardness tests were conducted according to ASTM E384 standard with a microhardness tester (DuraScan) at a load of 200gf and a dwell time of $15 \mathrm{~s}$. Compression tests were performed at room temperature according to ASTM E9 standard, at a strain rate of $10^{-3} \mathrm{~s}^{-1}$. All the parts were mechanically tested except for the Ti6Al4V-2.5nYSZ HT which was eliminated from the compression test study because it presented a $4 \mathrm{~mm}$ long crack in the central region of the part after HIP.

\section{Results and discussion}

\subsection{Powder mixture characterization}

A powder blend of Ti6AI4V and 2.5wt\% of nYSZ (Ti6Al4V + nYSZ; hereafter) was investigated. Fig. 2 represents the morphologies of the as-received Ti6Al4V, nYSZ, and the Ti6Al4V + nYSZ powder blend. As can be seen in Fig. 2(a) and Fig. 2(b) that the asreceived Ti6Al4V powders exhibit a spherical morphology with a small fraction of powder satellites and nYSZ is in small agglomerates. It can be seen from Fig. 2(c-d) that nYSZ is homogeneously distributed over the Ti6Al4V powder. According to EDX analysis, nYSZ is homogeneously distributed over the Ti6Al4V powder grains. 

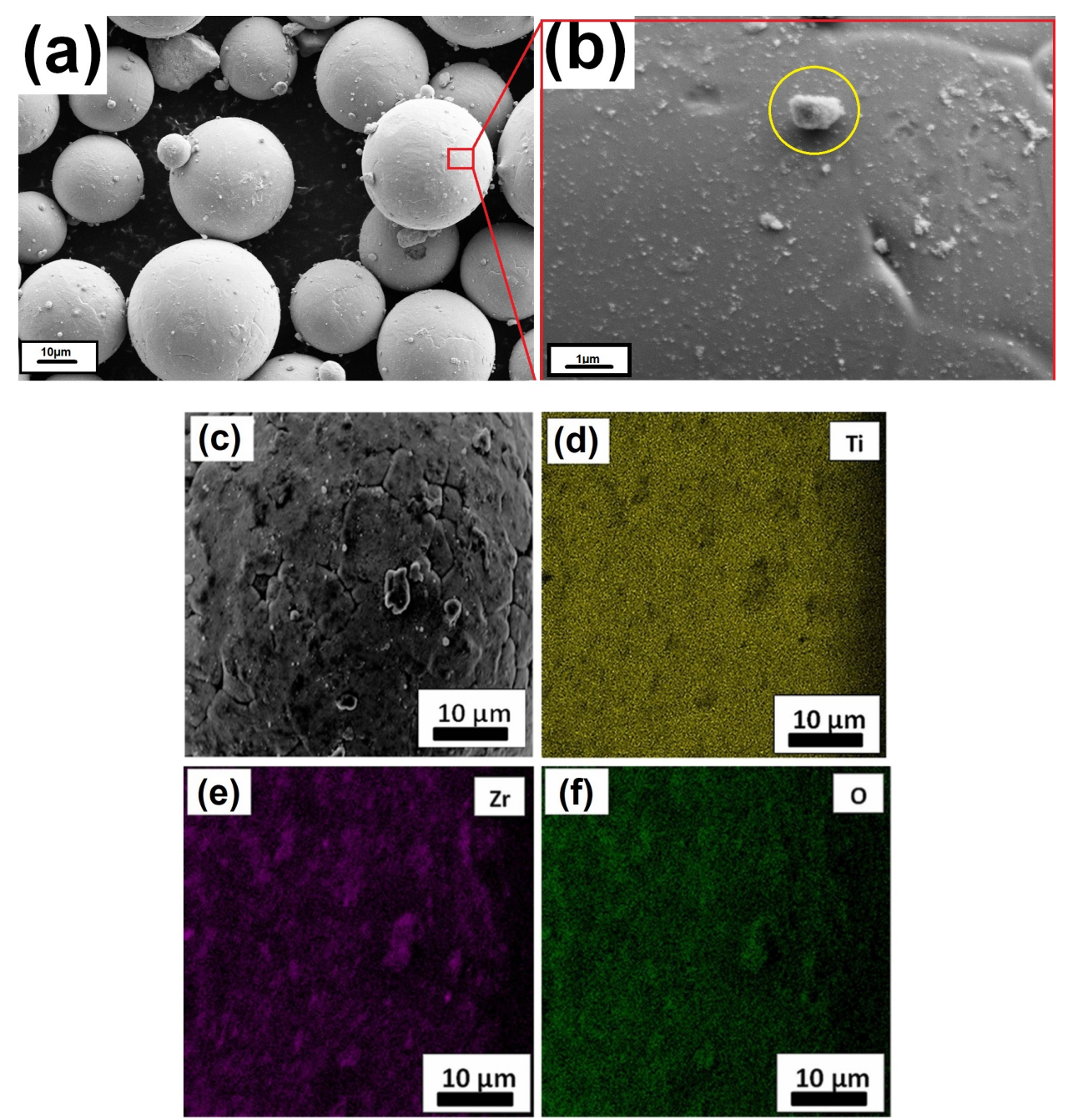

Figure 2: Particle shape morphology of the starting powders: (a) Ti6Al4V+nYSZ powder mixture used for melting; (b) Surface of one powder grain showing nYSZ circled in yellow; (c-f) EDX analysis of one powder grain of the Ti6Al4V+nYSZ powder mixture (c): one grain of Ti6Al4V+ nYSZ powder mixture, (d): Titanium, (e): Zirconium and (f): Oxygen

\subsection{Density measurements}

According to Fig. 3, all parts showed high relative mass densities, in the range 99.33 to $99.60 \%$. Ti6Al4V HT relative density was about $99.25 \pm 0.1 \%$. Adding nYSZ up to $2.5 \mathrm{wt} \%$, however, has dramatically enhanced the density of Ti6Al4V which showed a relative value of $99.6 \pm 0.2 \%$. The results are in line with previous reports [13-14]. HIP was applied (920 C $/ 2 \mathrm{~h} / 1000 \mathrm{bar})$ in order to enhance the parts density and eventually their mechanical behavior. Parts bulk density was measured (Fig. 3) using a He pycnometer and the results showed an increase in all parts density for Ti6AI4V HT HIP, Ti6AI4V-1nYSZ HT HIP, and Ti6AI4V-2.5nYSZ HT HIP. The HIP process was almost successful in eliminating most of the porosities; however, some residual porosities still exist after HIP. The elimination of porosity by using HIP could be good for other mechanical properties such as fatigue. In the case of Ti6Al4V-2.5nYSZ HT HIP, a small crack was noticed after removing the part from the HIP chamber. Therefore, in order to avoid any errors during density measurements, the fractured area was cut and removed. 


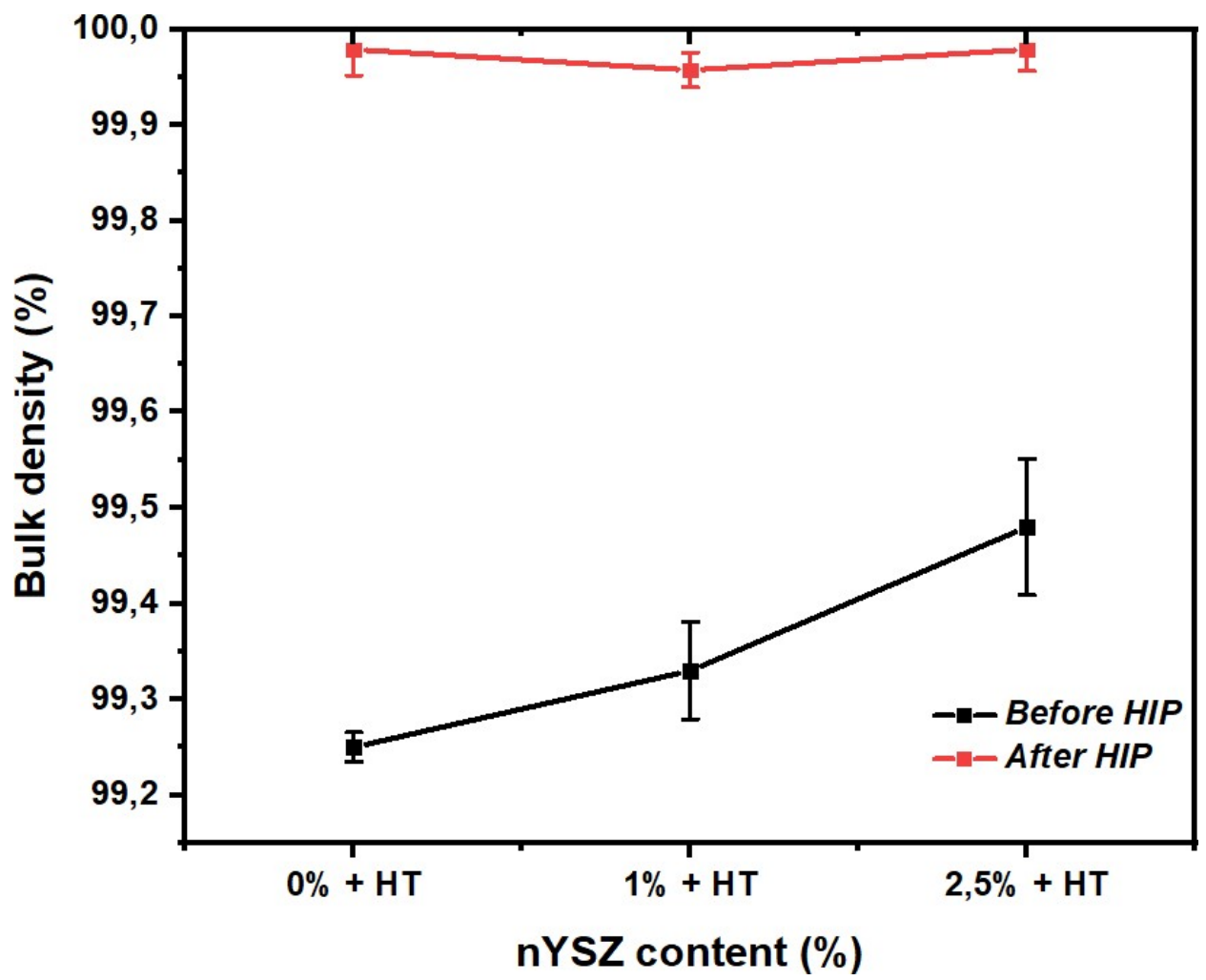

Figure 3: Effect of nYSZ addition and HIP over bulk density of Ti6Al4V HT $(0 \%+H T)$, Ti6Al4V-1nYSZ HT (1\%+HT), and Ti6Al4V2.5nYSZ HT (2.5\%+HT)

\section{3. $X$-ray diffraction analysis (XRD)}

XRD phase detection was performed with $\left(20^{\circ}<2 \theta<90^{\circ}\right.$ and $\left.\Delta 2 \theta=0.03^{\circ}\right)$, using Cu Kal $(\lambda=0.154056$ nm) radiation source with an INEL Equinox 1000 X-ray diffractometer. XRD characterization was performed by using: MATCH software for phases identification analysis [15].

According to Fig. (4), the as-received Ti6Al4V powder present mostly a titanium a phase. The addition of nYSZ to the as-received Ti6Al4V powder showed the appearance of a mixture of Titanium a, monoclinic and tetragonal nYSZ as it is seen in the Ti6Al4V+nYSZ powder mixture pattern. All parts showed a mostly a phase. It is noticed also that the Ti6Al4V HT peaks are shifting toward lower angles and that they seem to be narrower compared to the as-built state, this observation is probably due to stress relief effect and therefore lattice modification [16]. The addition of $1 \mathrm{wt} \%$ and $2.5 \mathrm{wt} \%$ of nYSZ partially stabilized the $\beta$ phase of Ti6Al4V, the appearance of $\beta$ phase could be attributed to the fact zirconia played the role of a $\beta$ stabilizer [12] in the Ti6Al4V matrix during melting via SLM. Following the $\alpha$ and $\beta$ peaks positions in the reinforced materials, it is observed that the addition of $\mathrm{nYSZ}$ also shifted the $\alpha$ and $\beta$ peaks towards lower angles in reference to Ti6Al4V + nYSZ powder mixture. In addition, all peaks are getting more narrower compared to Ti6AI4V + nYSZ powder mixture and the Ti6AI4V HT. However, when HIP post-processing was applied, the Ti6AI4V HT HIP, Ti6AI4V-1nYSZ HT HIP, and Ti6Al4V-2.5nYSZ HT HIP peaks were shifted to higher angles compared to their heat-treated state as seen in Fig. 4(b) this may be due to the solute redistribution at high HIPing temperature, which could introduce a lattice change and defaults reduction. After HIP the Ti6AI4V HT showed a small peak of $\beta$ phase, these findings were also reported by S. Leuders et al 2012 [17], however in the case of the reinforced and HIPed materials no $\beta$ peak was observed. 

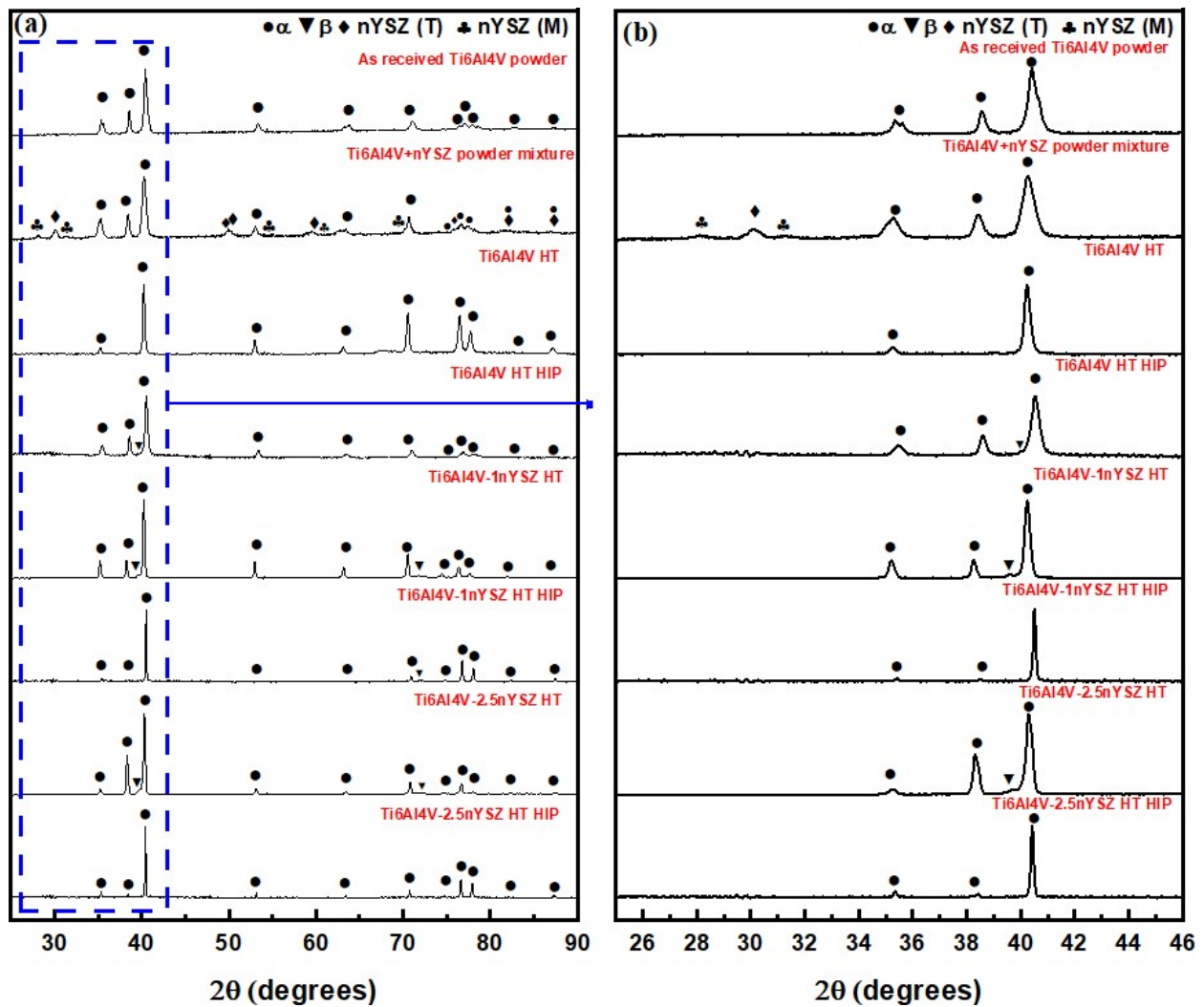

Figure 4: (a) XRD patterns of the as-received powders and their melted parts $(b)$ zoom over 2 theta $\left[25-46^{\circ}\right],\left(\alpha:(\bullet), \beta:(\nabla)\right.$, T: $^{\circ}$ Tetragonal ( $\bullet$ ) and M: Monoclinic ( $(\bullet))$.

\subsection{Bulk parts characterization}

Fig. 5 presents some EBSD maps obtained in Ti6Al4V HT, Ti6AI4V-1nYSZ HT and Ti6AI4V-2.5nYSZ HT and their HIPed parts, for which the color code indicates the major length of the lamellar grains. It is noticed that the a lamellar of Ti6Al4V HT, Ti6Al4V1nYSZ HT, and Ti6AI4V-2.5nYSZ HT are getting smaller in length when the nYSZ percentage increases. After HIPing the previous parts, the a grains become much wider compared to the heat-treated materials. In the case of the Ti6Al4V, HIPed close to the transus temperature, the a phase within the matrix tends to nucleate along the boundaries, expelling the $V$ atoms, leading to the formation of a $\beta$ phase at $a$ phase boundaries [18]. Hence during HIP treatment, the long a needles are transformed into the long and thick a lamellae. Indeed, according to XRD data, a small fraction of the $\beta$ phase was noticed after HIPing Ti6Al4V HT. In the case of HIPed Ti6Al4V-1nYSZ HT and Ti6Al4V-2.5nYSZ HT, it is observed that a lamellar grains have also grown in length. The variation in lamellar length in the HIPed case materials was also compared, and it can be noticed that Ti6AI4V HT HIP and Ti6Al4V-1nYSZ HT HIP had almost the same grain size distribution. However, for Ti6Al4V-2.5nYSZ HT as well as for the Ti6Al4V2.5nYSZ HIP material the grains growth seems to be retained and the grains are smaller than in HIPed Ti6AI4V HT. 

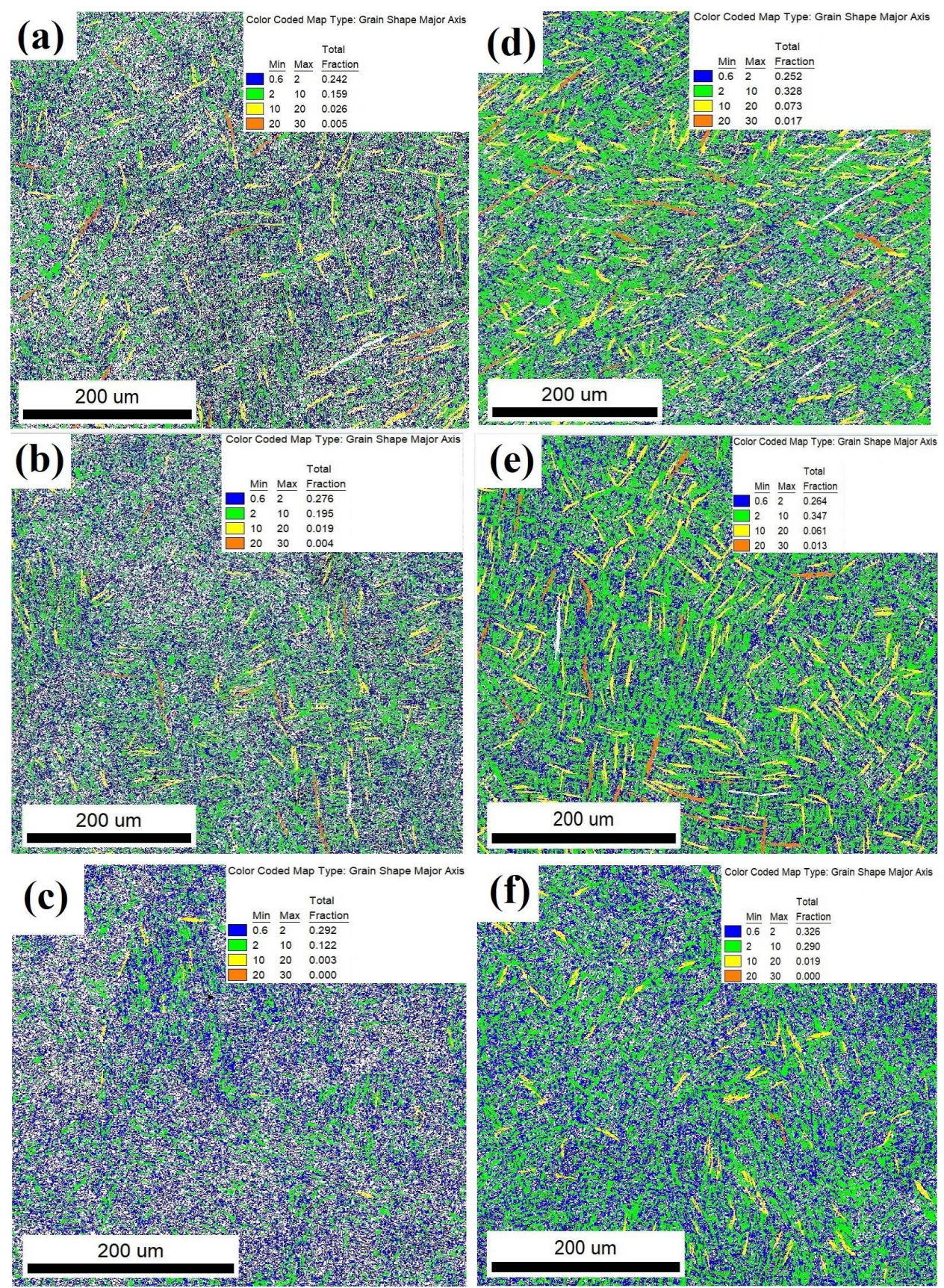

Figure 5: Mapping of $\alpha$ lamellar length SEM images of bulk materials (a) Ti6Al4V HT, (b) Ti6Al4V-1nYSZ HT (c) Ti6Al4V-2.5nYSZ HT. (d), (e) and (f) are theirs HIPed materials respectively (data extracted from EBSD analysis)

Grains width was also investigated (Fig. 6), it is observed that all materials showed thicker grains when HIP is applied as observed from Fig. 6 in the case of Ti6AI4V HT, the width of the grains increased after HIP. In the case of Ti6Al4V-1nYSZ HT the width of the a grains was increased. However, compared to the HIPed Ti6Al4V HT, a decrease was noticed. In the case of Ti6AI4V-2.5nYSZ HT, one can notice that the width continues to decrease beyond the limit of detection via EBSD at this scanning step size ( $0.6 \mu \mathrm{m})$ this means that width can be even lower. In the case of Ti6Al4V-2.5nYSZ HT, the width of the lamella decreases drastically compared to the HIPed Ti6AI4V HT and Ti6Al4V-1nYSZ HT. The change in grains width and length plays a major role in mechanical properties of these materials in addition to nano reinforcement effect. 

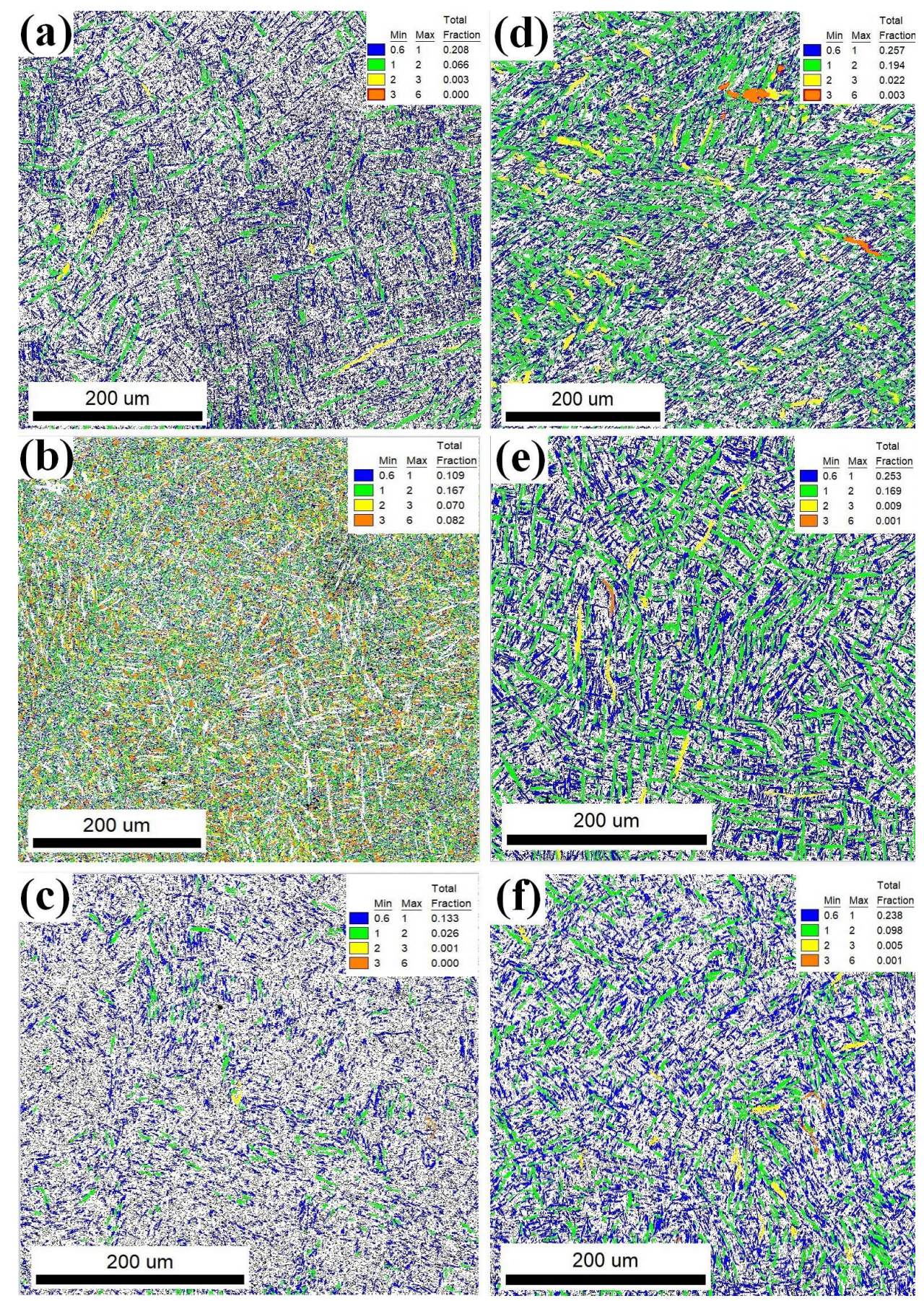

Figure 6: Mapping of $\alpha$ lamellar width of bulk materials (a) Ti6Al4V HT, (b) Ti6Al4V-1nYSZ HT (c) Ti6Al4V-2.5nYSZ HT. (d), (e) and (f) are theirs HIPed materials respectively (data extracted from EBSD analysis)

\subsection{Mechanical properties}

\subsubsection{Microhardness tests}

It can be noticed from Fig. 7 that the microhardness of the Ti6Al4V HT is equal to be $408 \mathrm{HV}$. The higher hardness of Ti6Al4V HT compared to as-built state is probably due to $\mathrm{Ti}_{3} \mathrm{Al}$ precipitates formation after heat treatment as reported in previous work [19]. The addition of $1 \mathrm{wt} \%$ and $2.5 \mathrm{wt} \%$ of nYSZ improves, further, the microhardness to 441 and $512 \mathrm{HV}$, respectively. Together with optimized SLM melting parameters that produced nearly full density and the addition of $2.5 \mathrm{wt} \%$ of nYSZ thus results in the elaboration of homogenous oxide dispersion strengthened alloy with enhanced mechanical properties. After applying HIP post- 
processing, however, the microhardness of Ti6Al4V HT, Ti6AI4V-1nYSZ HT, and Ti6AI4V-2.5nYSZ HT is reduced to 360,409 and 493 HV respectively: this could be due to the grain size evolution reported above.

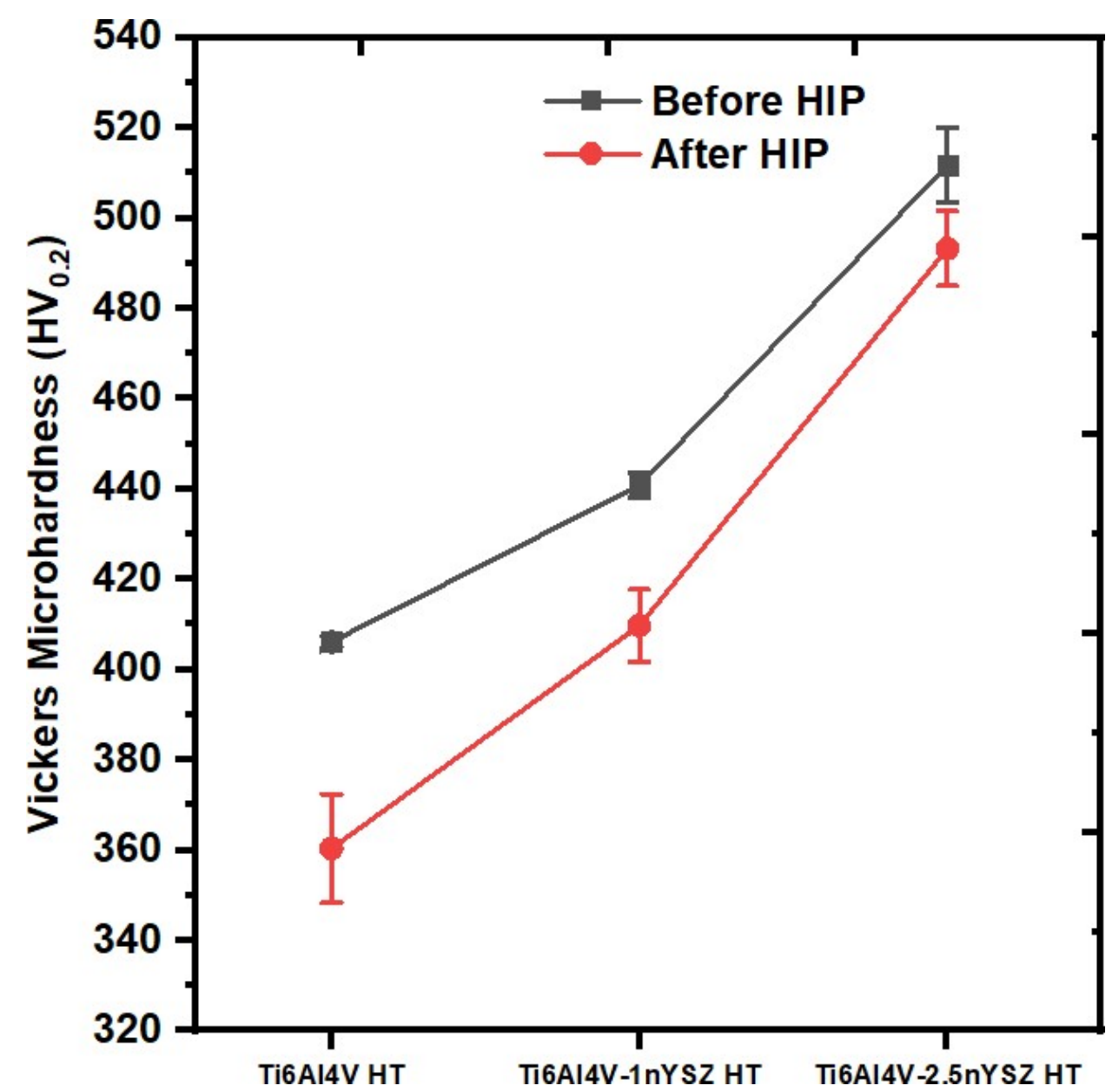

Figure 7: Effect of nYSZ addition and HIP on the average Vickers microhardness of Ti6Al4V processed by SLM. Ti6Al4V (Ti6AI4V as built), Ti6Al4V HT (0\%+HT), Ti6Al4V-1nYSZ HT (1\%+HT) and Ti6Al4V-2.5nYSZ HT (2.5\% + HT).

\subsubsection{Compression test results}

Three compression tests per material were carried out. The loading axis was taken perpendicular to the SLM building direction. The tests were performed using an MTS compression machine at a strain rate of about 10-3 s-1. The curves were obtained without extensometer. The compression stress-strain data are presented in Fig. 8. The compression data of the HIPed Ti6Al4V2.5nYSZ HT were not plotted because of the small fracture that was noticed after HIP. All the parts were machined in order to have specimen adapted to the compression test.

Ti6Al4V HT presents a maximum compressive stress and yield strength of about $1337 \pm 10 \mathrm{MPa}$ and $960 \pm 10 \mathrm{MPa}$ respectively. These values are consistent with previously published data [20]. However, when HIP is applied, these values slightly decrease to $1300 \pm 6 \mathrm{MPa}$ and $922 \pm 5 \mathrm{MPa}$ respectively as shown in Fig. 8. this decrease in strength was accompanied by an improvement in 
plastic strain from $22.61 \% \pm 2 \%$ to $29.71 \% \pm 1 \%$. In order to explain these changes in the strength and strain after HIP in terms of microstructure, one can recall first that a previous study has shown that the strength of Ti6AI4V HT could be better explained in terms of grain width than in terms of grain length [21], this study indeed showed that the strength of materials decreases when the a lamellar grains width decreases. This is also observed in the present case (see Fig. 5 and Fig. 6). In the case of Ti6Al4V-1nYSZ $\mathrm{HT}$ the maximum compressive strength and yield strength were increased to $1427 \pm 40 \mathrm{MPa}$ and $1110 \pm 30 \mathrm{MPa}$ respectively. These values are higher than those obtained for Ti6Al4V HT; this increase in strength could be attributed to both combined factors of grains refinement as seen in Fig. 5 and Fig. 6 and nYSZ that could play a significant role in dislocations impediment. When Ti6Al4V-1nYSZ HT is HIPed, the maximum strength is increased to almost $1555 \pm 10 \mathrm{MPa}$ and yield strength to $1190 \pm 15$ MPa compared to Ti6Al4V-1nYSZ HT. This observation is not consistent with the observation of a reduction of dislocation density (as seen by XRD) and of an increase in grain size (as seen in EBSD). After HIP, the Ti6Al4V-1nYSZ HT plastic strain was increased from $13.33 \% \pm 2 \%$ to $19.25 \% \pm 1 \%$, this could be more consistent with the observed increase of grain thickness. One can notice, the plastic strain was not drastically decreased in the case of Ti6Al4V-1nYSZ HT compared to Ti6Al4V HT before and after HIP which is an important factor in some applications.

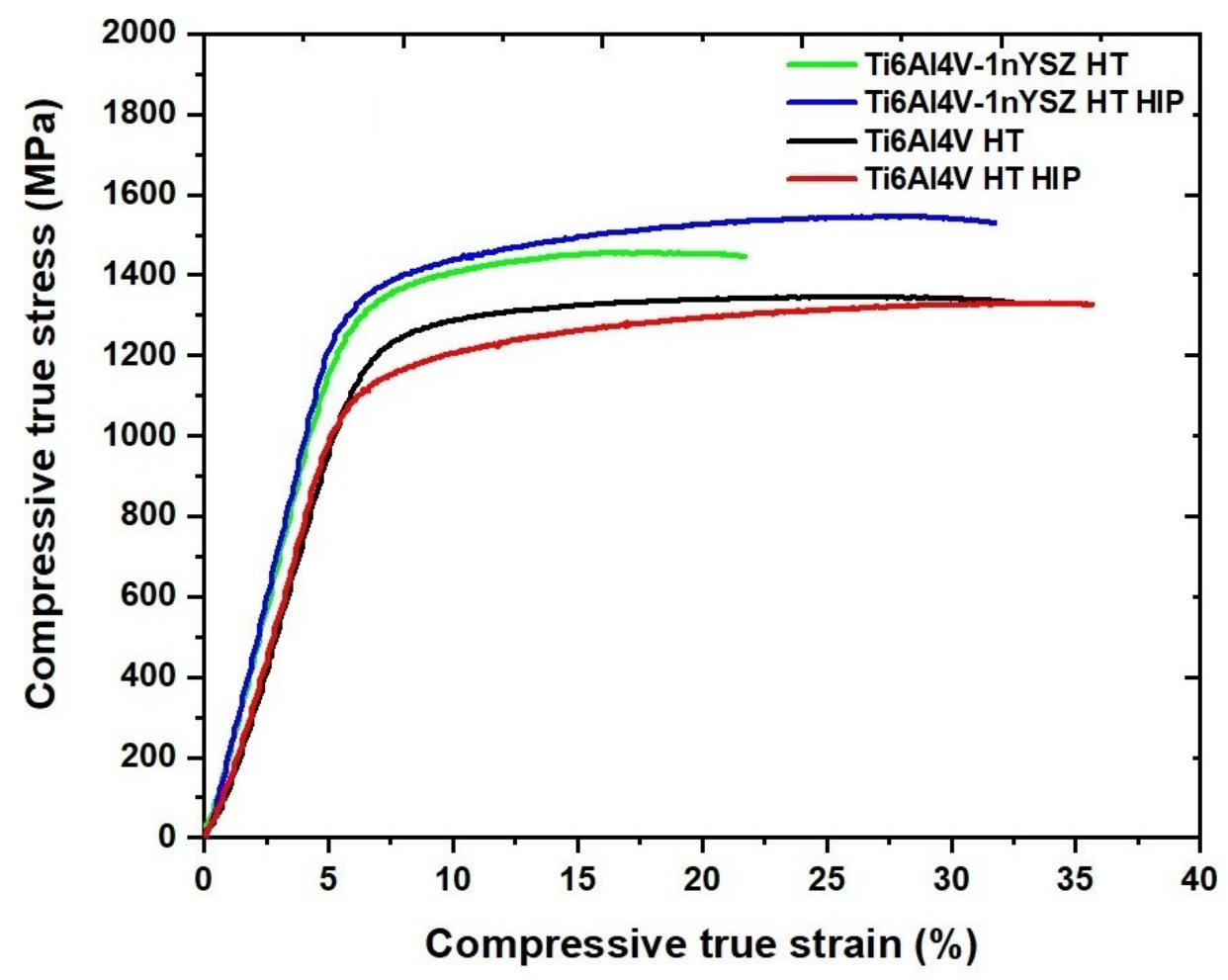

Figure 8: Compression true stress-true strain plots of SLMed Ti6Al4V HT and Ti6Al4V-1nYSZ HT (Before and After HIP)

\section{Conclusion:}

Ti6Al4V reinforced with nYSZ parts were successfully manufactured via selective laser melting technology. The parts showed a very high density of about $99.60 \%$. Parts density were greatly increased after applying HIP post-processing up $99.98 \%$. The length and width of the lamellae were reduced after the addition of $2.5 \mathrm{wt} \%$ of nYSZ. a lamellar grains shape changed after HIP. The microhardness was greatly increased after nYSZ addition and slightly reduced after HIP processing. The compressive strength and the yield strength of nYSZ reinforced Ti6AI4V were enhanced compared to Ti6Al4V HT. The ductility of Ti6Al4V was maintained 
after the addition of $1 \mathrm{wt} \%$ of nYSZ. HIP post-processing increased the ductility of all materials and slightly enhanced the compressive strength of Ti6Al4V reinforced by $1 \%$ wt of nYSZ.

\section{$\underline{\text { Reference }}$}

[1] C.K. Chua, K.F. Leong, 3D printing and additive manufacturing: principles and applications, 5th ed., World Scientific Publishing Company, (2017).

[2] I. Inagaki, T. Takechi, Y. Shirai, N. Ariyasu, Application and features of titanium for the aerospace industry, Nippon Steel \& Sumitomo Metal Technical Report 2014, pp. 22-27.

[3] R. Huang, M. Riddle, D. Graziano, J. Warren, S. Das, S. Nimbalkar, J. Cresko, E. Masanet, Energy and emissions saving potential of additive manufacturing: the case of lightweight aircraft components, J. Clean. Prod. 135 (2016) 1559-1570.

[4] C.K. Chua, K.F. Leong, 3D printing and additive manufacturing: principles and applications, 5th ed., World Scientific Publishing Company, (2017).

[5] S. Pouzet, P. Peyre, C. Gorny, O. Castelnau, T. Baudin, F. Brisset, C. Colin, P. Gadaud, Additive layer manufacturing of titanium matrix composites using the direct metal deposition laser process, Mater. Sci. Eng. A. 677 (2016) 171-181.

[6] H. Attar, M. Bönisch, M. Calin, L.C. Zhang, K. Zhuravleva, A. Funk, S. Scudino, C. Yang, J. Eckert, Comparative study of microstructures and mechanical properties of in situ Ti-TiB composites produced by selective laser melting, powder metallurgy, and casting technologies, J. Mater. Res. 29 (2014) 1941-1950.

[7] P. Krakhmalev, I. Yadroitsev, Microstructure and properties of intermetallic composite coatings fabricated by selective laser melting of Ti-SiC powder mixtures, Intermetallics. 46 (2014) 147-155.

[8] H. Attar, S. Ehtemam-Haghighi, D. Kent, M.S. Dargusch, Recent developments and opportunities in additive manufacturing of titanium-based matrix composites: A review, International Journal of Machine Tools and Manufacture. 133 (2018) 85-102.

[9] S. Pouzet, Fabrication additive de composites à matrice titane par fusion laser de poudre projetée, PhD Thesis, Paris, ENSAM, 2015.

[10] T.K. Gupta, F.F. Lange, J.H. Bechtold, Effect of stress-induced phase transformation on the properties of polycrystalline zirconia containing metastable tetragonal phase, Journal of Materials Science. 13 (1978) 1464-1470.

[11] X.B. Zhou, J.T.M. De Hosson, Reactive wetting of liquid metals on ceramic substrates, Acta Mater. 44 (1996) $421-426$.

[12] B. Zhang, B. Ma, X. Zhang, Q. Zhu, X. Ren, Y. Zhang, X. Qu, J. Yu, J. Yu, Effects of YSZ and nano-ZrO 2 contents on the properties of Ti2448-ZrO 2 biomedical composites fabricated by SPS, Ceramics International. 44 (2018) 13293-13302.

[13] X.-Y. Zhang, G. Fang, S. Leeflang, A.J. Böttger, A. A. Zadpoor, J. Zhou, Effect of subtransus heat treatment on the microstructure and mechanical properties of additively manufactured Ti-6Al-4V alloy, J. Alloys Compd. 735 (2018) 1562-1575.

[14] H. Attar, M. Bönisch, M. Calin, L.-C. Zhang, S. Scudino, J. Eckert, Selective laser melting of in situ titanium-titanium boride composites: Processing, microstructure and mechanical properties, Acta Mater. 76 (2014) 13-22.

[15] Match! Phase Identification from Powder Diffraction, http://www.crystalimpact.com/match/].

[16] B. Wysocki, Bartłomiej, P. Maj, R. Sitek, J. Buhagiar, K. Kurzydłowski, et W. Więszkowski, Laser and Electron Beam Additive Manufacturing Methods of Fabricating Titanium Bone Implants, Appl. Sci. 7 (2017) 657.

[17] S. Leuders, M. Thöne, A. Riemer, T. Niendorf, T. Tröster, H.A. Richard, H.J. Maier, On the mechanical behaviour of titanium alloy TiAl6V4 manufactured by selective laser melting: Fatigue resistance and crack growth performance, International Journal of Fatigue. 48 (2013) 300-307.

[18] B. Vrancken, L. Thijs, J.-P. Kruth, J. Van Humbeeck, Heat treatment of Ti6Al4V produced by Selective Laser Melting: Microstructure and mechanical properties, Journal of Alloys and Compounds. 541 (2012) 177-185. 
Compounds. 764 (2018) 1056-1071.

[21] Tiley, Jaimie "Modeling of Microstructure Property Relationships in Ti-6Al-4V." Electronic Thesis or Dissertation. Ohio State University, 2003 